\title{
Should teachers use L1 in EFL classroom?
}

\author{
Shahnaz Mahmud \\ Shahjalal University of Science and Technology, Sylhet, Bagladesh
}

\begin{abstract}
English language teachers customarily rule out the use of mother tongue for teaching English. Reflecting on the theoretical underpinnings and empirical research on the use of mother tongue (L1) in English classroom and its ongoing debate the present study aims to explore teachers' and students' perceptions of it. A mixed method approach using questionnaire and interview is employed to analyze Bangladeshi university teachers' and students' belief and perceptions of teaching English with the help of L1. The study also attempts to discuss the strengths and weaknesses of using L1. Results indicate that both teachers and students perceive the necessity of judicious use of L1 to facilitate learning and acquisition of English as a foreign language (EFL).
\end{abstract}

Key words: mother tongue (L1), Bangla, English as a foreign language, monolingual, bilingual.

\section{Introduction}

English should solely be used in English language classroom has been a matter of extensive debate and has often become an issue of ambivalence to teachers whether it is prudent to use mother tongue in the English as a Foreign language (EFL) classroom. The debate initiated from the common resolute view that mother tongue (L1) blocks the process of acquiring the target language (TL) while the other view claims L1 use is the verification of learning the target language. In addition to this, different theories over decades have provided different hypothesis about the value of L1 use in second language (L2) classroom. Researchers (Asher, 1993;
Chaudron, 1988; Halliwell, \& Jones, 1991; Krashen et al., 1984; Macdonald, 1993; Wong-Fillmore, 1985) agree that input in the target language is the gateway to successful language acquisition to occur and learners should get the opportunity of a second/ foreign language environment to practice and thereby develop their language skills. The traditional second language (L2) teaching pedagogy, Grammar Translation Method (GTM)promoted bilingual method of teaching emphasizing on the facilitative role of mother tongue in the target language learning. This approach received heavy criticism and was disowned by new school complaining of the negative effects of L1 on learning process. The school propounding monolingual approach, such as Direct 
Method (DM) and Audio Lingual Method (ALM) believes that L1 has no essential role in classroom, its use rather interferes second language (L2)/ target language (TL)/ foreign language (FL) learning process; by taking recourse to mother tongue students would be blocked out of target language exposure (Bouangeune, 2009; Ellis, 1985).This assertion remains unjustified in a non-native EFL environment and is largely not supportedby any empirical evidence (Bhooth, Azman \& Ismail, 2014). The proponents for using L1 (supported by humanistic and communicative methodology) argue that its judicious use would help learners develop the skill for comprehensibility of the target language (Atkinson 1987; AlNofaie 2010; Auerbach, 1993; Machaal 2012; Nation 2003; Salah \& Farrah 2012; Sharma 2006; Spada \& Lightbrown, 1999;Storch\& Wigglesworth 2003;Swain \& Lapkin 2000; Tang 2002). Despite the abundance of research on underlying principles and approachesfor teaching English common assumption still exists that learners' mother tongue should be abandoned and its use discouraged (Sa'D \& Qadermazi, 2015). The language teacher in a monolingual large classroom of less proficient students often finds himself ina predicament as to which to adhere-the monolingual approach or the bilingualapproach to teaching English language. The current study intends to provide insights into the perceptions of teachers and students for L1 instruction in English classroom and how the use of L1 could be an effective tool for teaching English language

The study is conducted in the perspective of English language teaching and learning in Bangladesh where the mother tongue
Bangla proudly holds the country's linguistic, cultural and sovereign identity. The study looks at teaching and learning of EFL from the perspective of L1use (in this case Bangla) in the universities in Bangladesh. A mandatory course in the universities in Bangladesh, the English language course aims at enhancing the language proficiency of the students so that they can meet the language requirements during their study in the universities and empower themselves with linguistic and communicative competence required in the work placements in future years. Although they study English as a compulsory subject since their primary schools, majority are of the students are found to lack competence in English language. Personal observations during lessons in the class reveal that some students just are not in the level of comprehending the simplest utterances in English. Many universities in Bangladesh do not conduct a separate test to evaluate admission seekers' level of academic English proficiency. Because of their inadequate proficiency, some students find the foundation English language course at the university problematic as it is a subject/ course that they had endeavored for long 12 years but all resulted in little improvement. So, question may arise as how do teachers manage the medium of instruction (MOI) in English as a foreign language (EFL) classroom and to what extent. The present study outlinesteachers' and students' perceptions about why teachers should or should not use L1 in their English classroom, discusses and provides insights into the strengths and weaknesses of using L1 in the teaching of English as a foreign language in Bangladeshi universities. More specifically, this study will study in detail teachers' and students' perceptions of the use of Bangla as a 
complementary to the MOI in English language classroom as well as its role in facilitating the up gradation of students' English language proficiency.

\section{Literature review}

Teachers all over the world assume a discreet autonomy regarding their beliefs, perceptions and knowledge of teaching methodology. They at the same time follow some model to identify themselves in the customary praxis of teaching. Literature abounds in plenty relating to the contention of using mother tongue in L2 classroom. The present section intends to provide an overview of the research pertaining toit.

The prevalence of L1 use in teaching target language as prescribed in GMT turned out to be uncommunicative and irrelevant (Harmer, 2001) as it could not produce proficient English language learners even after years of study.Brown (2000, p.16) spotted it as doing "virtually nothing to enhance students' communication ability in the language". As a reaction to the overwhelming translation practice of GMT, newer methods in the 1970s and 1980s such as the Direct Method and ALM advocated banning of L1 use and emphasized for a monolingual approach arguing that

a) Instructions in English classroom should be carried out exclusively in the target language without recourse to students' L1 (Cummins, 2007)

b) Translation between L1 and L2 has no place in the teaching of language or literacy (Cummins, 2007)

Such instructional pedagogy underscores that L1 use rather interferes and impedes the acquisition of L2. Emphasis on only English use can enhance communication in a way that it will develop an attitudinal and behavioral change in the learner, he will be able to internalize the language and use fluently. Sharma (2006) provides a psychological rationale for using L2 only, "the more students are exposed to English, the more quickly they will learn; as they hear and use English, they will internalize it to begin to think in English; the only way they will learn it is if they are forced to use it" (p.80). Sharma (2006) concludes that L1 use should be judicious as long as it facilitates learning English effectively, saves time and makes students relaxed and motivated in the lesson. Supporting minimal use of L1, Krashen and Terrell (1983) argue that learners acquire L2 as they acquire their L1 in their childhood.

Studies conducted in recent decades assert that L1 has a functional role in the classroom discourse which facilitates students' learning. Stern (1992) sees the use of L1as "a natural psychological process in second language development" (p. 286). David Atkinson (1987, p.241) suggests a series of use of L1 in EFL classroom discourse:

a. Eliciting Language: "How do you say ' $X$ ' in English?"

b. Checking comprehension: "How do you say 'I've been waiting for ten minutes in Spanish?" (Also used for comprehension of a reading or listening text.)

c. Giving complex instructions to basic levels

d. Co-operating in groups: Learners compare and correct answers to exercises or tasks in the L1. Students at times can explain new points better than the teacher.

e. Explaining classroom methodology at basic levels 
f. Using translation to highlight a recently taught language item

g. Checking for sense: If students write or say something in the L2 that does not make sense, have them try to translate it into the L1 to realize their error.

h. Testing Translation items can be useful in testing mastery of forms and meanings.

i. Developing circumlocution strategies: When students do not know how to say something in the L2, have them think in different ways to say the same thing in the L1, which may be easier to translate.

On a similar note, Atkinson (1987) provides a rationale for using L1 suggesting that translation helps students to give voice to their feelings and avoid negative transfer of L1. He suggests that teachers can use L1for functional purposes such as checking comprehension, giving instructions, enhancing cooperation among learners and improving presentation and reinforcement. Furthermore, Atkinson incorporatedselective use of L1 into communicative methodology and concluded that "L1 can be a valuable source if it is used at appropriate times andin appropriate ways".

In the same year, Elsa Auerbach (1993, p.29) gives a sociopolitical rationale for the use of L1 in ESL classrooms suggesting that L1 provides a sense of security and validates learners' lived experiences facilitating them to express themselves in English without hesitation. Auerbach (1993) suggests the following possible occasions for using the mother tongue: negotiation of the syllabus and the lesson; record keeping; classroom management; scene setting; language analysis; presentation of rules governing grammar, phonology, morphology, and spelling; discussion of cross-cultural issues; instructions or prompts; explanation of errors; and assessment of comprehension.

Within the same context, Sipra (2007) supporting the facilitative role of L1 concluded that a teacher having the knowledge of both the target and mother tongue is able to provide better input than a monolingual teacher. According to Cangarajah (1999) "accommodation of L1 in English classroom does not hamper the acquisition of L2, but enhances it" (p. 143).

Having similar view, Macaro (2001) argues that L1 is an important resource to learning the target language because it assists convenient comprehensibility. According to Harbord (1992), ELT teachers who use only English have been found not successful enough in getting their meaning across, resulting to student incomprehension and resentment. Mc Millan and Rivers (2011) are of the view that selective use of the L1 can "play important cognitive, communicative and social functions in L2 learning" (p. 252). Aqel (2006) in his study of teachers' and students' reactions to using their L1 in teaching EFL recommends a judicious use of Arabic in EFL teaching since L1 helps to make L2 meanings comprehensible to low proficiency learners easily. Similar suggestions are also found in studies such as Schweers (1999), Cole (1998), Bouangeune (2009). Woodall(2002) observed L1 as an important resource in L2 learning arguing that code-switching occurs instinctively to all language learners.

To summarize this section it could be said that researchers have revealed the positivity of limited and judicious use of L1 in English language classroom for classroom management, lesson instruction, problem solving, grammar and new vocabulary explanation, translating words 
or vocabulary or sentences to convey meaning. Researchers have observed actual practices in classroom, investigated the function and purposes of L1, conducted survey in institutions under specific contexts, explored the amount of use of L1 and investigated the perceptions of teachers. Though relevant research abounds in exploration of the current issue, it seems confusion still prevails among practicing teachers about the extent of use of L1. The current study is not limited to teachers' perceptions only; it investigates both the perception of the teachers and students regarding teachers' use of L1. The study also explores the strengths and weaknesses of mother tongue in a context where a traditional and official strict English-policy is expected to be practiced and maintained. Though the study is conducted in Bangladesh context, its pertinence is expected to be observed in the surrounding Asian and wider foreign language teaching context.

\section{The study}

The study attempted to explore the following research questions

- What are the Bangladeshi EFL teachers' and students' perceptions regarding teachers' use of L1 (Bangla) in classroom?

- What are the strengths and weaknesses of teachers' use of L1 in teaching EFL?

\section{Context and participants}

The present research was carried out in the 2017-2018 academic session of a public and a private university in Bangladesh during the English Language Foundation courses studied by students in the first yearof undergraduate programs. These courses focusing on review of grammar items and language skillsaim improve students' English language proficiency which they are expected to have acquired from twelve years of education in their schools and colleges.

The participants comprised of 10 teachers and 60 students selected through purposive sampling using the homogenous technique. Purposive sampling involves "deliberate selection of sample from particular settings, people or events for getting information which otherwise cannot be acquired from other sources" (Maxwell, 1998, p. 87).

The teachers have different educational backgrounds from home and abroad and various years of experience in teaching English. Among them, 3 teachers possess PhD degrees with 15-17 years of teaching experience, 3 teachers have 8-10 years of experience in teaching English and hold MA degrees in ELT (Bangladesh) and TESOL (from UK). The rest 4 teachers hold Masters degree in English Literature and Language and have been teachers since 2013 or 2014.

The participant students aged between 1922 years studied in the departments of Genetic Engineering and Biotechnology, Biochemistry and Molecular Biology, Textile Engineering and Fashion Design and Technology. Being natives of a monolingual countryBangladesh, the students' language profile comprises practice and use of English language only during their time in the English classroom. Majority of them studied in Bangla medium schools with little or no opportunity to communicate in English outside their English classroom which turned out to be a classroom with monolingual linguistic competence. Nonetheless at the university they get exposure to English since the medium of instruction (MOI) is at large English. The use of Bangla in the classrooms is strictly limited to oral production by both the teachers and the students. The English 
course contents do not include any Bangla reading or writing or any translation task.

\section{Instrument}

The study adopted a mixed method approach for the investigation of the research problem. The mixed method approach involved collection of quantitative close ended (using self report questionnaire) data and qualitative open ended (employing semi-structured interview) data with the purpose to obtain a detailed understanding and corrobation of information which would otherwise be lacking if only one method was used. Quantitative data helped to collect broader opinion on the research issue while the qualitative data helped to elaborate, clarify and corroborate results building on the findings. The content validity was verified by two colleagues, experts in ELT and Applied Linguistics. Following their comments, necessary modification was applied to the instruments.

\section{Self- report Questionnaire}

The questionnaire adapted from Shabir (2017) which explored a similar research was used to tap into the participants attitudes towards L1 use. Two questionnaires one for the teachers and another for the students comprised of 22 items about teachers' and students' perceptions of the function and strengths and weaknesses of L1 instruction in their EFL classroom. Respondents were asked to indicate the frequency of occurrence on a 5-point Likert scale (strongly disagree, disagree,agree and strongly agree). The questionnaire for teachers had Cronbach's alpha value of .90 and the second questionnaire for students had Cronbach's alpha value of .87 .

\section{Focus group semi-structured interview}

Qualitative data with a purpose to validate the questionnaire data was obtained by interviewing selected number of participants individually at different times as scheduled by the researcher. Predetermined questions were prepared in order to prompt respondents and elicit their deeper thoughts. Towards the end of participant students' language course 20 of them were interviewed to tap more deeply into their mind. All the teachers were also interviewed to back up the questionnaires and triangulate the data.

\section{Procedure}

Students were given the questionnaire in their classroom with assertion that their responses would in no way affect their academic grades in the university. Questionnaires were sent to the teachers with request to fill in and return them in their convenient time during the semester.Datawas calculated in term of the percentage on every statement and then mean was calculated to measure the degree of overall opinion about each statement.

The present study is qualitative in essence with frequencies offered at times for elaboration of the information collected through the instruments. Data were analyzed by calculating the number of respondents who agreed or disagreed to different degrees with the different aspect specified by each statement included in the survey.

\section{Result and discussion}

This section presents and discusses the findings from questionnaire and interview with both teachers and students. 


\section{Questionnaire findings: Teachers' responses}

The data revealed equal frequency of opinion of teachers on many questionnaire items (such as item 1, 3, 4, 5, 6, 8, 9, 10, 11, 12, 17 and 21) and differences of opinion onthe rest of the items. 7 to 9 teachers' equivalent opinion of agreement and strong agreementis observed for the items 1, 3, 4, $5,6,8,9,12$ and 21. Almost all the teachers agreed and strongly agreed that use of L1 might habituate studentsinto using L1all the time(item 4 and mean is 4.7), its use should be at a minimal level(item 8 and mean is 4.8), students prefer teachers' use of L1 to explain new vocabulary, difficult grammar and concepts (item 1,3 and 6 and mean is $3.6,3.7$ and 4.3 respectively), and students use of L1 help them to express themselves fully and clearly (item 21 and mean is 3.7). Furthermore, 9 teachers supported that they do not themselves prefer to use L1 as it does more harm than benefit (item 12, mean is 4.1).

Higher frequency of opinions of disagreement to the statements in the questionnaire can be observed for items 9 , $10,11,17$ and 22. 9 teachers disagreed that they ask students the L1 meaning of words or sentences as a comprehension check (item 11and 22 and mean is 1.9 and 1.7 respectively). 6 disagreed and 2 strongly disagreed, 2 agreed that students should translate a text into their L1 while reading (item 9, mean is 2.3), 7 disagreed that a student should know the Bangla meaning of every word (item 10 and mean is 2.8). Differences of opinions are also observed in the responses of item 13, 15, 1619 and 20. 5 teachers are of the opinion that L1 use relieves students from their apprehensionof not comprehending language whereas the other 5 disagree to this proposition (item 16 where mean is 2.8). 3 teachers agree that it is essential to know the Bangla meaning of English words while the rest 7 disagree to its necessity.Data also revealed that teachers ( 3 disagreed while 5 agreed and 2 strongly agreed to item 13) sometimes speak in L1 for explanation and clarification of topics/or concepts. 5 teachers agreed and 2 strongly agreed to the proposition that they feel disappointed when they see students speaking in Bangla (item 14). 1 remained neutral while another teacher disagreed to this statement.

\section{Students' responses}

Students' response shows a similar preference for teachers' using Bangla (L1) in the classroom. The mean calculations revealed an overwhelming preference for use of Bangla for explaining difficult grammar, vocabulary and concepts (item $1,3,4$ and 6 where mean calculated are 3.93, $3.73,4.08$ and 3.86 respectively). Their apprehension of the disadvantage of Bangla use is also revealed from their agreement to item 5, 7, 8, 18. Accordingly majority agreed that the more are taught in Bangla, the more they would become habituated to its comfortable and easy (item 5; the mean is 3.65), L1 use should be restricted (item 8 and mean is 3.75) as students will get less exposure to English (item 7 and mean is 3.16) and so medium of instruction should be English (item 18 where mean is 3.26). However, they also agreeand strongly agree that they feel at ease when teacher talks, explains in Bangla (item 19 and 20, where mean amounted to 3.56 and 3.90 respectively). Majority also agreed that the use of Bangla helps them to express themselves clearly and efficiently (item 21, mean is 3.66) and reduces anxiety and inhibition (item 16, 17, the mean being 3.3).

\section{Interview findings: Teachers' response}

Data collected from interview assisted in gathering teachers' and students' thoughtful opinions and views about use of Bangla in classroom. The foremost opinion of all the teachers is that L1 should not be 
encouraged, English should be the sole medium of instruction in the English class to provide exposure to language and consequently enrich students' understanding of communicative English. Occasional and judicious use of Bangla is acceptable only when the teacher assumes its necessity. They try not to use Bangla except in situations where they realize that students did not comprehend the presented item such as a complex idea or a method of grammar or any genre writing. In a classroom of diverse proficiency level of students, teachers sometimes have to switch to the native language to grab the students' attention, maintain some degree of interest, create comfortable atmosphere, to explain meaning of words, sentences or concepts and make learning experience enjoyable. This switching functions as a resource for the students who suffer from apprehension of inadequate language proficiency. This finding correlates with Greggio and Gil (2007), Morahan (2007) which pointed out that teachers code switching is targeted at clarification of the difficulties in language.

\section{Students' response}

Response of students in the interview session also revealed their preference for their teachers to use L1 though in a restricted range. Students want their teachers to use Bangla for some explanation of difficult grammar, new topics, and when it is difficult to understand in English. Followings are some of the responses of students:

- The teacher must talk in Bangla when we find English difficult

- Sometimes we request the teacher to explain in Bangla when we don't understand the English.

- We ask the teacher to narrate the prescribed literary text in Bangla so that it helps us to understand easily when we read the text ourselves.

- Bangla explanation helps us to understand a reading text. Banglaexplanation makes the comprehension of the text in short time.

- If we can't understand in English teacher should only use Bangla to help us learn English.

- Bangla helps me to exchange my ideas and opinions clearly without the need to talk in English and run the risk of misunderstanding.

The most interesting finding of all is that students themselves are aware that excessive use of L1 would not facilitate their learning. They complained that they do not appreciate it if teacher uses Bangla for simple and easy matters, which otherwise could have been avoided. But at the same time they all acknowledge the benefits of Bangla especially as a scaffolding tool, i.e. translate words, explaining difficult grammar.

It is interesting to note that every participant is aware of the benefit of using English as the sole language in EFL classroom. But they also believe that L1 can act as a scaffolding resource to get help from in case of incomprehensibility. Herein lies the strength of L1. On the other hand, it is important that students acquire the comprehensible skill for understanding FL in the class. They have to be accustomed to the target language as much as possible without any explanation in their L1. Students overwhelming preference for teachers instruction in Bangla for expediency and efficacy of information transmission and clarification is justified if it is strictly limited to introduction of new and complex lesson/ idea/ concept/ vocabulary/ grammar point. Bangla can be 
used as a resource that both teachers and students can share when it is pre-requisite.

The findings of the present study are in congruence with those of other studies (Machaal 2012; Salal\&Farrah 2012; Nation 2003; Tang 2002; Al Nofaie 2010; Sharma, 2006; Storch\&Wigglsworth, 2003) in the contexts of Nepal, Australia, Saudi Arabia, Palestine, China.

From the analysis it is revealed that both teachers and students prefer L1 use only when the degree of incomprehensibility is high. Thus the strength and weakness of L1 could be assumed to depend on the time, place and manner of its use and how successful the teacher is in conveying the message when he needs to cater to different learner styles and abilities.

The objective of this small exploratory piece of research is to study teachers' and students' perception of teachers' use of Bangla in the EFL classrooms and the strengths and weaknesses of its use. The findings from data collected through questionnaire and interview indicated that the teachers out rightly do not oppose Bangla use but they call for its judicious application. They believe English should be the main source of input and students should get accustomed and internalize English language linguistic and communicative features, so that they begin to think and produce in English. Sometimes teachers cannot avoid using L1owing to the inadequate proficiency of majority of students in the classroom. Two of the teachers elaborated that use of L1 to support EFL development can be considered from humanistcic approach which allows students to say what they want in their mother tongue. L1 can assist a learner as a scaffolding tool in circumstances where he needs backing referred to as his zone of proximal development (Vygotsky, 1978). By identifying students' zone of proximal development (ZPD) teachers can locate their style and strategies and accordingly plan more targeted instruction for them. Use of L1 could be tailored according to the ZPD of individual students. However, this instruction strategy would be more effective and advantageous in a small classroom size.

\section{Conclusion}

The present study revealed various pedagogical functions of Bangla (L1) ranging from explanation of meaning, grammar, complex patterns of language and building rapport with students. Bangla can be used as an effective tool for EFL development. As stated in the beginning of the article that there exists no empirical evidence supporting total obstruction of L1 in EFL classroom (Bhooth, Azman \& Ismail, 2014)teachers can switch codes because of the mixed abilities of EFL learners which would help lower students' affective filter (Krashen 1985).

English plays a dominant role in tertiary education in Bangladesh. Teachers should be cautious to use mother tongue in an effective way as an operative tool. Teachers should introduce awareness raising activities to persuade learners to use the target language.

It is important for teachers to realize that in cases where either the students are competent in English or not, or either L1 is allowed or banned in English classroom, the use of L1 cannot be totally avoided. The judicious use of L1 may enhance the acquisition process and encourage learners to focus on similarities and differences between mother tongue and target language. 


\section{References}

Al-Nofaie, H. (2010). The attitudes of teachers and students towards using Arabic in EFL classrooms in Saudi public schools.Novitas ROYAL (Research on Youth and Language) 4(1), 64-95.

Aqel, F. (2006). Using mother tongue (Arabic Language) in EFL. Journal of Educational Sciences.University of Qatar, 9

Asher, C. (1993). Using the target language as the medium of instruction in the communicative classroom: The influence of practice on principle. Studies in Modern Languages Education, (1), 225-238.

Atkinson, D. (1987). The mother tongue in the classroom: A neglected resource? ELT Journal. 41(4), 241-247.

Auerbach, E. (1993).Reexamining English only in the ESL classroom.TESOL Quarterly. 27(1), 9- 32.

Bhooth, A., Azman, H., \& Ismail, H. (2014). The role of the L1 as a scaffoloing tool in the EFLnreading classroom.Procedia - Social and Behavioral Sciences, 118, 7684. Retrieved from doi: 10.1016/ j.sbspro.2014.02.011.

Bouangeune, S. (2009). Using L1 in teaching vocabulary to low English proficiency level students: A case study at the University of Laos'. English Language Teaching Journal 2(3), 186-193.

Cangarajah, A. S. (1999). Resisting linguistic imperialism in English teaching. Oxford University Press.

Chaudron, C. (1988). Teacher talk in second language classrooms. In M. H. Long, \&J. C. Richards (Eds.), Second Language
Classroom (pp. 50-87). Hawaii: Cambridge University Press.

Cole, S. (1998). The use of L1 in communicative English classrooms.JALT Journal.39(2), 95-101.

Greggio, S., \& Gil, G. (2007).Teacher's and learner's use of code switching in the English as a foreign language: A qualitative study. Linguagem $\mathcal{E}$ Ensino, 10, (2), 371-393.

Halliwell, S. \& Jones, B. (1991). On target teaching in the target language. London: Centre for Information on Language Teaching and Research.

Krashen, S. D. (1985). The input hypothesis: Issues and implications. New York: Longman.

Krashen, S. D., Terrell, T. D., Ehrman. M. E., \& Herzog, M. (1984). A theoretical basis for teaching the receptive skills.Foreign Language Annals, (17), 261- 275.

Macaro, E. (2001). Analyzing student teachers' code switching in foreign language classrooms: Theories and decision making. The Modern Language Journal, 85 (iv), 531-548. Retrieved fromhttps:// doi.org/10.1111/00267902.00124.

Macdonald, D. (1993). Learners and modified/negotiated interactions: what works for pronunciation. Language Learning, (32), 201-227.

Machaal, B. (2012). The use of Arabic in English classes: A teaching support or a learning hindrance? Arab World English Journal 3(2), 194-232.

Maxwell, J. A. (1998). Designing a qualitative study. Handbook of Applied Social Research Methods.69-100. 
McMillan, B. A., \& Rivers, D. J. (2011). The practice of policy: Teachers attitudes toward "English only". System, (39), 251-263.

Morahan, M. (2007). The use of students' first language (L1) in the second language (L2) classroom. Retrieved from http:/ / www.labschool.pdx.edu/ PD_Mini_Modules/images/8/81/ MorahanL2inL1class.pdf.

Nation, P. (2003). The role of the first language in foreign language learning.Asian EFL Journal 5(2). 1-8

Sa'D \& Qadermazi. (2015). L1 Use in EFL Classes with English-only Policy: Insights from Triangulated Data. CEPS JournalVol.5 (2), 162- 175

Salah, N. M. H. \& Farrah, M. A. H. (2012). Examining the Use of Arabic in English Classes at the Primary Stage in Hebron GovernmentSchools, Palestine: Teachers' Perspectives. Arab World English Journal 3(2): 400436.

Shabir, M. (2017). Student-teachers' beliefs on the use of L1 in EFL classroom: A global perspective. English Language Teaching.Vol 10(4).45-52.

Sharma, B. K. (2006). Mother tongue use in English classroom.Journal of NELTA 11(1), 80-87.

Schweers, W. (1999).Using L1 in the L2 classroom. English Teaching Forum 37(2), 6-13.

Storch, N. \& Wigglesworth, G. (2003). Is there a role for the use of the L1 in an L2 setting? TESOL Quarterly $37(4), 760-769$.
Swain, M. \&Lapkin, S. (2000). Task-based second language learning: The uses of the first language. Language Teaching Research 4(3), 251-274.

Tang, J. (2002). Using L1 in the English classroom. EnglishTeaching Forum, 40(1), 36-43.

Wong-Fillmore, L. (1985). When does teacher talk work as input? In S. M. Gass \& C. M. Madden (Eds.), Input in second language acquisition (pp. 17-50). MA: Newbury House.

Vygotsky, L. S. (1978).Mind in society: The development of higher psychological processes. Cambridge, MA: Harvard University Press. 


\section{Appendix 1}

Teacher's questionnaire

\begin{tabular}{|c|c|c|c|c|c|}
\hline Statements & 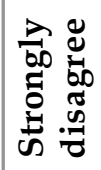 & 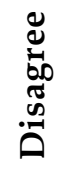 & 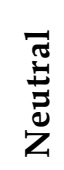 & 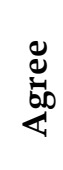 & 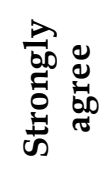 \\
\hline $\begin{array}{l}\text { 1. My students like it when I use L1 to explain } \\
\text { grammar rules. }\end{array}$ & & & & & \\
\hline $\begin{array}{l}\text { 2. My students like my use of L1 for classroom } \\
\text { management (e.g. giving instructions and } \\
\text { groupings students). }\end{array}$ & & & & & \\
\hline $\begin{array}{l}\text { 3. My students like my use of L1 to explain the } \\
\text { meaning of a new vocabulary. }\end{array}$ & & & & & \\
\hline $\begin{array}{l}\text { 4. When I use L1 in English classrooms students will } \\
\text { tend to speak more L1 than English in the } \\
\text { classroom. }\end{array}$ & & & & & \\
\hline $\begin{array}{l}\text { 5. The more I make use of L1, the less effort students } \\
\text { make to understand my use of English. }\end{array}$ & & & & & \\
\hline $\begin{array}{l}\text { 6. My students understand me when I use English } \\
\text { to explain simple grammatical terms and concepts } \\
\text { but want me to explain difficult terms and } \\
\text { concepts in L1. }\end{array}$ & & & & & \\
\hline $\begin{array}{l}\text { 7. Teachers should not use L1 in English classrooms } \\
\text { because it reduces the amount of students' } \\
\text { exposure to English. }\end{array}$ & & & & & \\
\hline $\begin{array}{l}\text { 8. The use of L1 should be minimized in English } \\
\text { classrooms. }\end{array}$ & & & & & \\
\hline $\begin{array}{l}\text { 9. Students should translate English language into } \\
\text { L1 while reading a text. }\end{array}$ & & & & & \\
\hline $\begin{array}{l}\text { 10. The only way to learn an English word completely } \\
\text { is to know its meaning in L1. }\end{array}$ & & & & & \\
\hline $\begin{array}{l}\text { 11. I like to ask my students to translate a word or } \\
\text { sentence into L1 as a comprehension check. }\end{array}$ & & & & & \\
\hline
\end{tabular}




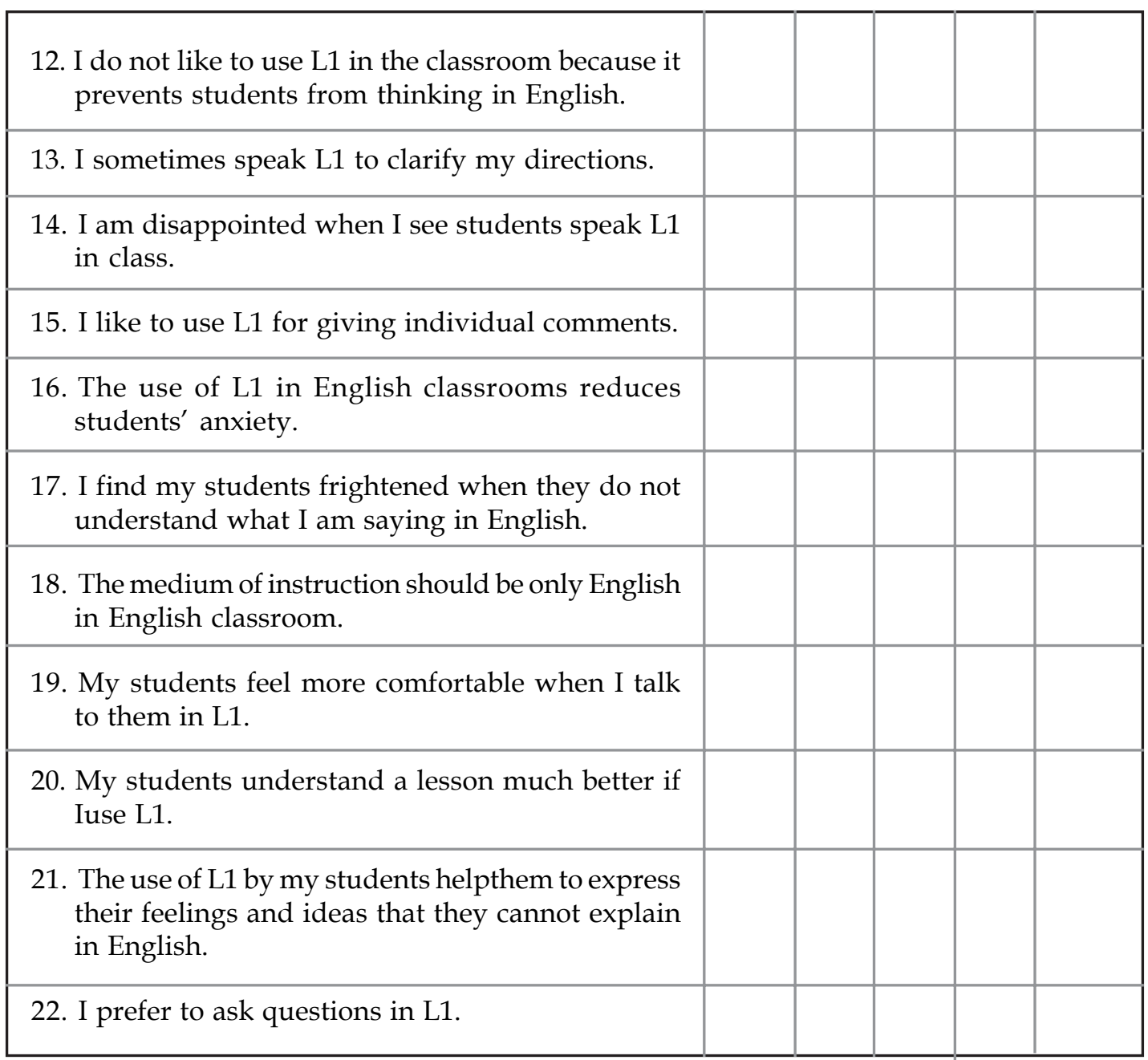




\section{Appendix -2}

Students' questionnaire

Ref: Cooperation in research.

\section{Dear Student}

The following is a self- report questionnaire for data collection for a research on the role of Bangla in English language classroom. Your cooperationis needed to explore your opinion/ perception regarding the extent of use of Bangla in the English classroom. Would you tick (") the option (strongly disagree/ disagree/ agree/ strongly agree) you think best against the statements in the questionnaire attached? All individual responses would serve research use only and would not affect your academic performances. Moreover, your response would be kept confidential.

Thank you for your cooperation.

\begin{tabular}{|c|c|c|c|c|c|}
\hline Statements & 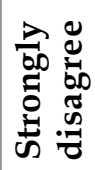 & 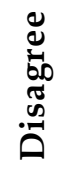 & 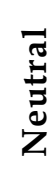 & 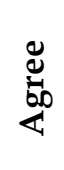 & 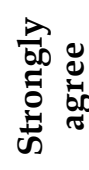 \\
\hline $\begin{array}{l}\text { 1. I like it when my teacher uses Bangla to explain } \\
\text { grammar rules. }\end{array}$ & & & & & \\
\hline $\begin{array}{l}\text { 2. I want my teacher to use Bangla for classroom } \\
\text { management (e.g. giving instructions and } \\
\text { groupings students). }\end{array}$ & & & & & \\
\hline $\begin{array}{l}\text { 3. I want my teacher to use Bangla to explain the } \\
\text { meaning of a new vocabulary. }\end{array}$ & & & & & \\
\hline $\begin{array}{l}\text { 4. When teacher uses Bangla in English classrooms, } \\
\text { students will tend to speak more Bangla than } \\
\text { English in the classroom. }\end{array}$ & & & & & \\
\hline $\begin{array}{l}\text { 5. The more I make use of Bangla, the less effort I will } \\
\text { make to understand my use of English. }\end{array}$ & & & & & \\
\hline $\begin{array}{l}\text { 6. I want my teacher use English for explaining simple } \\
\text { grammatical terms and concepts and Bangla for } \\
\text { more difficult terms and concepts }\end{array}$ & & & & & \\
\hline $\begin{array}{l}\text { 7. Teachers should not use Bangla in English } \\
\text { classrooms because it reduces the amount of } \\
\text { students' exposure to English }\end{array}$ & & & & & \\
\hline $\begin{array}{l}\text { 8. The use of Bangla should be minimized in English } \\
\text { classrooms. }\end{array}$ & & & & & \\
\hline
\end{tabular}




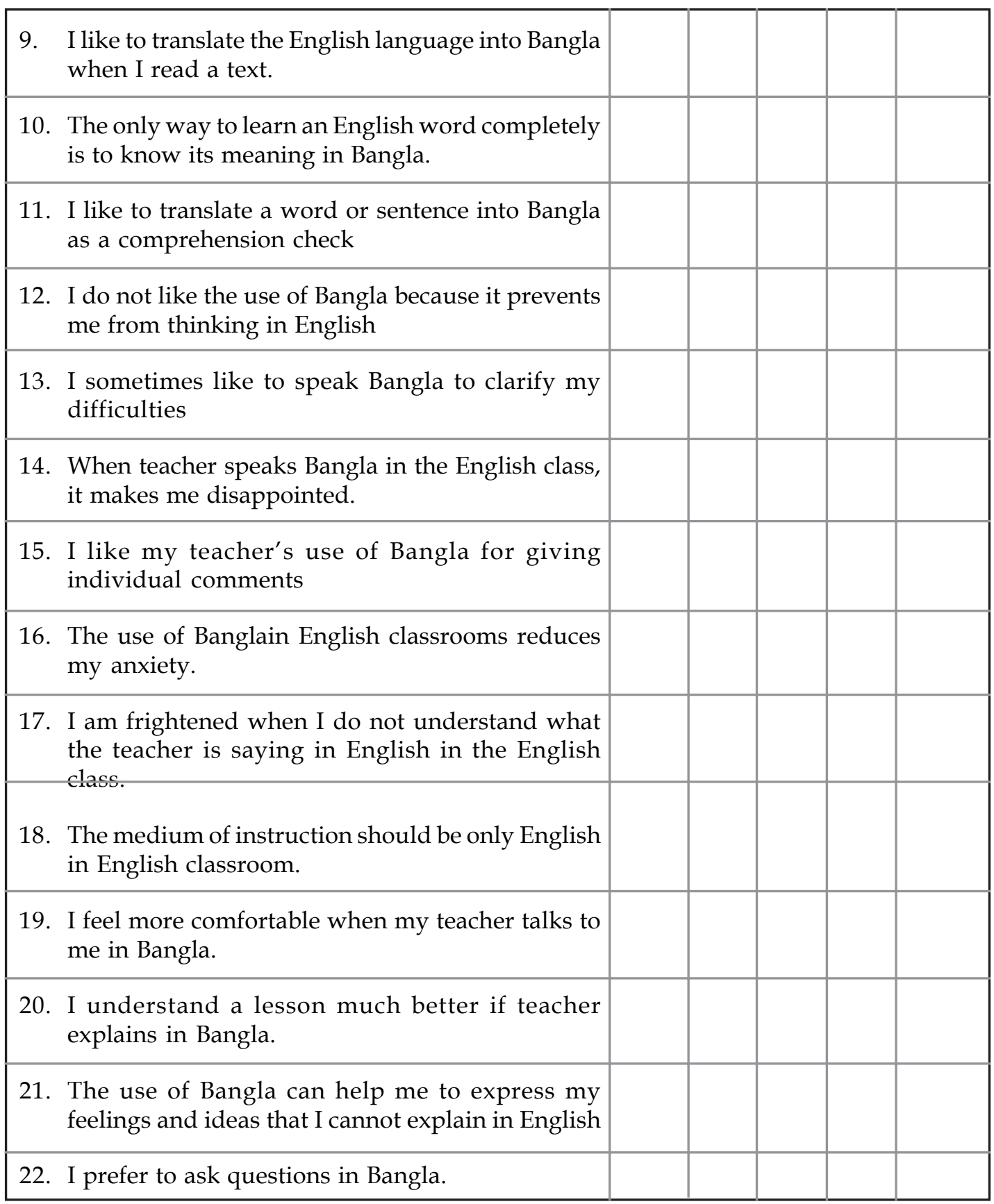

\section{Contributor}

Shahnaz Mahmud is Associate Professor in the Department of English at Shahjalal University of Science and Technology, Sylhet, Bangladesh. 